ISSN: 1130-3743 - e-ISSN: 2386-5660

DOI: http://dx.doi.org/10.14201/teoredu292233255

\title{
RELEVANCIA DEL PENSAMIENTO DE MICHAEL OAKESHOTT PARA LA EDUCACIÓN SUPERIOR CONTEMPORÁNEA
}

\author{
Relevance of Michael Oakeshott for contemporary high \\ education
}

\section{Importance de la pensée de Michael Oakeshott pour l'éducation supérieur contemporaine}

\author{
Santiago Tomás BeLLOMO \\ Universidad Austral. Escuela de Educación. C/ Mariano Acosta, 1611. \\ B1630FHB Pilar, Buenos Aires, Argentina.sbellomo@austral.edu.ar
}

Fecha de recepción: enero de 2017

Fecha de aceptación: marzo de 2017

RESUMEN

El presente trabajo se propone analizar el modelo de Universidad de Oakeshott, partiendo de los supuestos filosóficos que inspiran su teoría educativa general. El análisis pondrá en evidencia la vigencia de algunos de sus aportes y críticas a la educación actual. Al mismo tiempo, indagará respecto de las dificultades fácticas para la aplicación de sus propuestas en el contexto de la educación superior latinoamericana, y propondrá una revisión de la conceptualización misma a partir de la constatación de estas dificultades y a la luz de las orientaciones que el mismo Oakeshott postula en su filosofía educativa.

Palabras clave: Oakeshott; universidad; educación superior; educación liberal. 


\section{SUMMARY}

This article analyzes Oakeshott's model of University, and the philosophical principles that inspire his theory of education. The analysis evidences the deep relevance of some of Oakeshott's proposals and criticism. At the same time, it reveals some of the difficulties that arise when trying to apply his proposals. Following the trace of his own perspectives, the article will propose a revision of Oakeshott's philosophy of education in the light of these difficulties.

Key words: Oakeshott; University; High Education; Liberal Education.

\section{SOMMAIRE}

Cet article analyse le modèle de l'Université de Oakeshott, sur la base des hypothèses philosophiques qui inspirent leur théorie de l'éducation générale. L'analyse mettra en évidence la validité de certaines de leurs contributions et critiques de l'éducation aujourd'hui. Dans le même temps, il se renseignera sur les difficultés de fait dans la mise en ouvre de ses propositions dans le contexte de l'Amérique latine de l'enseignement supérieur, et de proposer une révision de la conceptualisation luimême de la réalisation de ces difficultés et à la lumière des lignes directrices que le même Oakeshott fait valoir dans sa philosophie de l'éducation.

Mots clés: Oakeshott; collège; enseignement supérieur; éducation libérale.

\section{INTRODUCCIÓN}

En su última etapa de producción intelectual, y antes de sumergirse en un largo y parsimonioso descanso -un descanso pródigo en cigarros y buen vinoOakeshott produjo una serie de artículos memorables que gozan aún de actualidad, tanto por su temática como por la agudeza de su estilo. Uno de ellos, "Un espacio de aprendizaje», de 1975, describe su propuesta educativa liberal, y alerta sobre los peligros que habitualmente la amenazan. Las reflexiones no son enteramente nuevas: apelan a temáticas tratadas en otros dos trabajos anteriores -El aprendizaje y la enseñanza, de 1965, y El concepto de universidad, de 1950-, y se hacen eco de habituales preocupaciones de la tradición «liberal»".

1. La tradición educativa liberal no necesariamente debe ser asimilada con el liberalismo político o económico propio de los regímenes de «derecha». Baqués (BAQués, 2014, 27) propone definir la concepción de Oakeshott como liberal conservadora, siguiendo así el pensamiento del mismo autor. Sullivan (Sullivan, 2014, 492), por su parte, señala la presencia de elementos de «izquierda» en el pensamiento de Oakeshott, lo que -a su entender- debe conducirnos a relativizar cualquier intento de vincular al autor tanto con la "derecha» como con la "izquierda». 
Los más de treinta años transcurridos desde la publicación de «Un espacio de aprendizaje» y el ámbito al que se dirige la publicación (el sistema universitario inglés) bien podrían inducirnos a pensar que las críticas de Oakeshott han perdido vigencia. Sin embargo, a pesar de las distancias contextuales y temporales, su mensaje sigue teniendo la capacidad de interpelar a educadores de distintas partes del mundo, aun cuando algunos aspectos de su pensamiento puedan resultar controvertidos. Cabe resaltar que la vigencia del autor y de su obra se ha visto revitalizada y magnificada con ocasión de su fallecimiento hacia fines de siglo pasado, lo que ha generado una inusitada multiplicación de comentarios y ensayos póstumos que aún hoy siguen proliferando ${ }^{2}$. En particular, su teoría de la educación -si acaso cabe hablar de "teoría" en su caso (Williams, 2009, 237)- ha inspirado y sigue inspirando gran cantidad de debates y publicaciones ${ }^{3}$.

El presente trabajo se propone analizar las reflexiones de Oakeshott sobre la actividad universitaria a la luz de las tendencias actuales que se advierten fundamentalmente en el ámbito de la educación superior. Para efectuar dicho análisis se propondrá inicialmente una breve caracterización de algunos supuestos sobre los que descansa su concepción educativa general. Su descripción permitirá efectuar un doble análisis - de factibilidad y de coherencia-, lo que contribuirá a profundizar la comprensión del autor y su vigencia y, al mismo tiempo, señalar interrogantes y eventuales críticas que sentarán las bases de futuras investigaciones.

\section{SuPUESTOS FILOSÓfICOS}

No es posible comprender la concepción educativa de Oakeshott ni su visión acerca de la educación universitaria si no es a la luz de los principios orientadores que configuran el conjunto de su producción intelectual (que se centra mayormente en cuestiones de filosofía política, antes que en temáticas educativas). Los principios que más nos interesan aquí son:

- Su análisis sobre la racionalidad humana y su crítica al racionalismo.

- Su consecuente teoría acerca del conocimiento humano.

- La noción de persona y de libertad.

- La importancia de la conversación.

- Los rasgos principales o notas de la educación.

A continuación, analizaremos brevemente cada uno de ellos.

2. La interesante reseña de Auspitz da cuenta del alcance de esta proliferación de escritos (AusPITZ, 2014).

3. En un artículo de 2010, Kevin Williams realiza una breve semblanza de las direcciones que han tomado las investigaciones póstumas en torno al pensamiento educativo de Michael Oakeshott (Williams, 2010). 


\subsection{La racionalidad humana y la crítica al racionalismo}

Oakeshott no es original en su valoración crítica del racionalismo. Antes bien, su reflexión se inserta en la extendida tradición antirracionalista que impregna muchas de las obras continentales e insulares de principios de siglo Xx. En «El racionalismo en política», describe -no sin ironías- los rasgos del racionalista clásico: éste aboga a favor del pensamiento libre, sin subordinarse a ninguna autoridad; es reformista, enemigo de lo establecido; mantiene una actitud a la vez escéptica y optimista, fundada en una confianza plena en el poder de la razón; es partidario de un igualitarismo intelectual individualista; subordina la experiencia colectiva al criterio propio; es generalista y carece de "entusiasmo negativo» (capacidad de reparar en los detalles); no tiene "atmósfera», vale decir, considera los procesos intelectuales aislados de su entorno; al tiempo que niega todo misterio, posee una marcada ansia de eternidad, en el sentido de padecer cierto "nerviosismo por lo transitorio" (Oakeshott, 2000a, 21).

Es evidente que la denuncia oakeshottiana padece el mismo defecto que todas las que apelan a "tipos ideales». En efecto, su crítica a los philosophes refiere a arquetipos antes que a personas de carne y hueso, aun cuando -al formularla- él reconoce tener en mente a unos "cuantos excéntricos» de su tiempo (Oakeshott, 2000b, 110). Sin embargo, este hecho no debe preocuparnos. La intención de la denuncia de Oakeshott parece estar encaminada a sentar las bases de su contrapropuesta. Su planteo es, de este modo, dialéctico: su crítica es sólo el bumus sobre el que está destinado a florecer un nuevo concepto de racionalidad.

En esto, la posición de Oakeshott también se inscribe en los avances intelectuales de la Inglaterra de su tiempo, que abogaba a favor de una ampliación del estrecho concepto de racionalidad heredado de la modernidad. Como señala Robert Grant, es curioso que Wittgenstein y Oakeshott transitaran los mismos pasillos de Cambridge durante casi 20 años sin siquiera trabar contacto (Grant, 1990, 14). Indudablemente, no son pocas las afinidades que pueden encontrarse entre las propuestas de ambos pensadores, aun a pesar de sus marcadas diferencias ${ }^{4}$.

Mientras que el concepto de razón heredado del racionalismo es anticipatorio, en el sentido de que se concibe como previo a la conducta y opuesto al capricho, al impulso o la improvisación, la nueva concepción de Oakeshott se pronunciará a favor de un matrimonio entre razón y conducta. La racionalidad se manifiesta primera y principalmente en la conducta, es una cualidad que acompaña la conducta. Sólo a posteriori se despliega en juicios independientes. La racionalidad es, pues, el "idioma de la actividad" (Oakeshott, 2000b, 122), un idioma que no siempre puede discriminarse de la actividad misma de la que aparece asociado. Esta evidencia inicial conlleva una primera distinción entre el conocimiento práctico (aquel que sólo

4. Para un análisis de las afinidades y diferencias entre el pensamiento de Wittgenstein y Oakeshott se sugiere la lectura de Plotica (Plotica, 2013), quien reconoce la afinidad del pensamiento del Wittgenstein de 1930 a 1950 con el Oakeshott de 1950 a 1980. 
se aprende en su uso y no es susceptible de formulación precisa e independiente), del técnico (que, surgiendo de la práctica, admite formulación posterior en juicios) o del científico (desarrollo ulterior que supone una cierta escisión de la actividad práctica original y originante) (Oakeshott, 2000b, 110).

Mientras que, en la tradición racionalista, la razón aparece sustantivada y ejerce su poder con independencia de la experiencia, la nueva concepción tendrá reparos en delimitar las fronteras existentes entre experiencia y racionalidad. Y no promoverá tampoco la ruptura con la experiencia colectiva que se forja en una cultura determinada. Por el contrario, la razón acogerá en sí la fuerza de la tradición precedente, ligada a las prácticas habituales de la sociedad en su conjunto. Ellas son tanto o más racionales que la argumentación silogística individual. La razón es primero ese "flujo de simpatía colectivo" (Oakeshott, 2000b, 130), esa comprensión tácita que subyace a la experiencia de la humanidad entera o de la tradición local regional. En segundo término, se convierte en patrimonio individual luego de un ejercicio de apropiación crítica de la mencionada tradición.

La diferencia no se limita a estos señalamientos. En tanto la aspiración racionalista reduce el patrimonio de la razón al universo de la consciencia y la reflexividad, la nueva concepción acoge en sí el inmenso legado de lo que es no reflexivo o prerreflexivo. Asimismo, mientras que la primera se refugia en el estrecho resquicio de la certeza que resulta de la autoevidencia, la segunda descansa en certezas que, de algún modo, son retransmitidas de generación en generación. De esta manera, es imprescindible reconocer la importancia de cierto tipo de fe, una fe que no tiene que ver necesariamente con la actividad religiosa sino con la confianza que despierta el legado de lo aprendido y aprehendido de otros. Así, lo que vuelve racional a una acción es su lugar en un flujo de simpatía, una corriente de actividad moral. Y si esta racionalidad no es objeto de certeza en sentido habitual del término, tampoco por ello carece de validez.

Bajo estos supuestos, Oakeshott se proponer ampliar el concepto de racionalidad. Este interés puede vislumbrarse ya en su primera producción, Experience and its Modes, de 1933, obra en la que -amparado en intuiciones posthegelianasidentifica los distintos modos que puede asumir la experiencia racional, que no es vista exclusivamente como una fuerza discursiva explícita. Según Fuller,

[...] un modo de experiencia no es sólo una perspectiva de las cosas. Es una versión disciplinada, aunque en última instancia delimitada de nuestra manera arbitraria, de la experiencia que se origina en ciertas suposiciones acerca de la forma en que debe explicarse el mundo, y que desarrolla con el tiempo métodos peculiares de indagación que crearán un cuerpo de conocimientos organizados y formas de conducta identificables que presentarán nuestro mundo de experiencia así como, de manera implícita, los actores de distintas disciplinas creen que hay que observar el mundo (Fuller, 2000, 24).

Los modos de experiencia o expresiones de distintos usos de la racionalidad son originalmente tres en 1933: la ciencia, la historia y la práctica. Esta visión 
multidimensional de la racionalidad se mantiene a lo largo de toda su vida, y va sufriendo variaciones que no alteran su inspiración original. En un artículo de 1959, "La voz de la poesía en la conversación de la humanidad», reconoce la trascendencia del lenguaje artístico como modo profundamente racional y legítimamente revelador de la experiencia humana (Oakeshott, 2000d, 465). Un año antes, Oakeshott había resaltado la diferencia existente entre la actividad de contemplación (entendida como revelación no reproductiva sino productiva, patrimonio del artista o del poeta) y la actividad práctica y la científica (Oakeshott, 2000c, 154-159). Sobre el final de su vida, queda claro que los modos de experiencia son cinco: el práctico o de la vida práctica, el científico, el histórico, el filosófico y el estético. En todas las clasificaciones, está implícito el reconocimiento de una diversidad de voces racionales, que se entrelazan en una conversación, como habrá de considerarse párrafos más adelante. Claro está que «en la conversación de la humanidad, de tiempo en tiempo, una voz podrá hablar más alto que otras, pero ninguna habrá de tener superioridad natural o primacía» (Oakeshott, 2000d, 465).

Como es fácil de imaginar, todo el concepto de educación de Oakeshott es solidario de esta visión acerca de la racionalidad. En particular, según indica Williams, «la concepción educativa de Oakeshott está basada en una rígida distinción que él traza entre el modo práctico y los restantes modos de experiencia» (Williams, 2009, 224). De esta distinción surge, como veremos, la discriminación entre la educación vocacional y la educación universitaria. De algún modo, la propuesta de Oakeshott se corresponde en este punto con la de John Henry Newman, quien en 1852 promoviera una visión de la enseñanza orientada a la "ampliación de la mente" -Enlargement of Mind o Mental Enlargement- (Newman, 1852) antes que a la búsqueda de fines utilitarios. Toda afición por el especialismo, todo cuerpo doctrinario centrado exclusivamente en un determinado modo de experiencia, restringe las capacidades y potencial de lo humano y es enemigo de la verdadera educación 5 . En rigor, el problema no es la especialización en sí misma, sino que la enseñanza ofrezca algo además de esto (Oakeshott, 2009a, 179). De lo contrario, se produce un empobrecimiento que redunda en perjuicio del desarrollo de la humanidad en su conjunto.

\subsection{El conocimiento bumano}

Lejos estaríamos de comprender a Oakeshott si dijéramos que la educación implica para él una tarea de conducción hacia la verdad. La noción de verdad es, en su particular visión, compleja. No se comprende qué es la verdad -afirma Oakeshott- si no es por referencia a la realidad y la experiencia. Cuando se habla

5. Tymothy Fuller dedica un ensayo específico a reseñar los puntos de acuerdo y las diferencias existentes entre la propuesta de Newman y la de Oakeshott, junto con la de Strauss. Encuentra en los tres pensadores una línea de continuidad en la defensa de la idea de aprendizaje liberal (FulLER, 2003). 
de «realidad", no se alude al universo de la "cosa en sí», a la objetividad de lo que es ajeno a la experiencia. La realidad no es otra cosa que esta experiencia subjetiva del mundo, que se construye en el mismo acto de percepción y que tiene, por sí, una naturaleza inconmensurable.

Oakeshott no nos propone, en rigor, una teoría gnoseológica acabada. El primer apartado de su última obra de importancia, On Human Conduct, titulado precisamente «On the Theoretical Understanding of Human Conduct», constituye tal vez la síntesis más completa de su concepción gnoseológica. El conocimiento es entendido aquí como una contingencia [going-on], una condición no deseada, de naturaleza falible e insegura (Oakeshott, 1975, 5). Constituye un compromiso de reducir el misterio, antes que de alcanzar una comprensión definitiva. Parte siempre de algo previamente comprendido, lo que habitualmente llamamos "dato» (Oakeshott, 1975, 1-2), pero se consolida como un proceso inacabado que no debe nunca ser confundido con un procedimiento (Oakeshott, 1975, 13). El conocimiento se consolida siempre en la frontera que separa lo aprendido y lo aún-no-aprendido. Este «dato» del que se parte no debe nunca ser confundido con la realidad:

Tal como yo lo entiendo, el mundo real es un mundo de experiencia dentro del cual el yo y el no-yo se revelan en la reflexión. No hay duda de que esta distinción es ambigua e inestable: es difícil (si no es imposible) encontrar algo que, en principio, pertenezca exclusivamente a cualquiera de los lados de la asociación. Pero en toda ocasión, aunque la incertidumbre puede subsistir en los bordes, no vacilamos en hacer esta distinción. Y lo que en toda ocasión se reconoce como yo se reconoce porque se separa de un no-yo presente: el yo y el no-yo se generan recíprocamente (Oakeshott, 2000d, 453).

Oakeshott profesa una posición idealista en su juventud, aunque, como él mismo reconoce, esta profesión se ejerce no sin reservas (Oakeshott, 1933, 7-8). El ser es, para él, el ser percibido. La experiencia, incluso sensorial, es pensamiento. Hay distintos modos de experiencia, que constituyen abstracciones, "mundos homogéneos de ideas» (Oakeshott, 1933, 75). Lo que llamamos, pues, «realidad» es identificable con lo que llamamos «experiencia». Ambos conceptos son también asimilables con el de "verdad", que no ha de ser concebida como el resultado de la actividad de contemplación, en el sentido escolástico de la palabra. No existe correspondencia ni visión de esencias (Oakeshott, 2000d, 467). Está visto que la teoría propuesta no es propiamente solipsista, en el sentido de admitir que somos sujetos encerrados en nuestro pensamiento. Es aún más radical: no es posible siquiera hablar de un sujeto hasta tanto no se genera esta dialéctica entre el acto de percibir y el de ser percibido (Oakeshott, 2000d, 454).

Pero el idealismo oakeshottiano no constituye una posición estática. Ha evolucionado de formas y en sentidos que los comentaristas no logran acordar suficientemente (Auspitz, 2014). Sin embargo, en su devenir no deja de transitar una cierta línea de continuidad que está caracterizada por tres rasgos principales: 1) el conjunto de su obra ofrece una "visión positiva», que nos aleja de fatalismos 
autoindulgentes, capitalizando la fragilidad de nuestra capacidad cognoscitiva para consolidar una "filosofía de la modestia». 2) Esta consciencia del límite cognitivo previene contra la aceptación de cualquier género de absoluto, 3) privilegiando el rol de la imaginación en la tarea de revelar la complejidad de la experiencia humana (O'Sullivan, 2002, 71-73).

\subsection{La noción de persona y de libertad}

Para Oakeshott, la cultura está conformada por contingencias, no por verdades eternas. Esas contingencias no se construyen azarosamente. Se corresponden con un legado, una tradición viva que conlleva en sí misma un mundo de significados (Oakeshott, 2009f, 43) ${ }^{6}$. En otras palabras, todo ser humano es heredero:

La herencia es un legado de logros humanos, de sentimientos, emociones, imágenes, visiones, pensamientos, creencias, ideas, interpretaciones, emprendimientos intelectuales y prácticas, lenguajes, relaciones, organizaciones, cánones y máximas de conducta, procedimientos, rituales, habilidades, obras de arte, libros, composiciones musicales, herramientas, artefactos y utensilios; en resumen, lo que Dilthey denominó un Geistige Welt. Los componentes de ese mundo no son abstracciones (objetos físicos) sino creencias (Oakeshott, 2009f, 69).

Esa herencia que se ofrece al sujeto humano no está al servicio del desarrollo de un patrón homogéneo. No existe una vida humana o un hombre perfecto y sustancial que le sirva de modelo para definir su conducta. "No existe tal cosa como la naturaleza humana; sólo hay hombres, mujeres y niños que responden con alegría o a su pesar, de manera reflexiva o no tan reflexiva, al peso de la conciencia, que existen sólo en función de su autocomprensión» (Oakeshott, 2009f, 49). Cualquier visión esencialista es, para Oakeshott, contraria a la libertad. El hombre «es lo que llega a ser; tiene una historia, pero no una naturaleza" (Oakeshott, 2009e, 94). En otras palabras,

tiene una "historia" pero no una "naturaleza»; es lo que llega a ser en su conducta. Esta "historia» no es un proceso evolutivo o teleológico. Es lo que realiza por sî mismo en un compromiso diario, la continua articulación de respuestas comprendidas ante permanentes situaciones emergentes que también son comprendidas de manera constante hasta que deja la escena diurna. Y si bien él podrá imaginar un carácter humano «ideal» y podrá usar este carácter para dirigir su auto-realización, no existe un hombre perfecto y último escondido en el fin de los tiempos o prefigurado en los caracteres que hoy caminan sobre la tierra (Oakeshott, 2009f, 41).

En este marco, lo que define a la persona humana es la libertad. Es la nota constitutiva; es, al mismo tiempo, una carga y una responsabilidad (Oakeshott,

6. Cf. también OAKESHOTт, 2009e. 
2009f, 36-39). Resulta necesario dotar de un doble sentido al término "libertad» para comprender su alcance: puede concebírsela como libre albedrío (y, en este caso, como propiedad de los actos humanos), o como capacidad autointerpretativa (como aptitud del hombre «de formular enunciados sobre sí mismo, en términos de su capacidad para interpretarse o, naturalmente, malinterpretarse a sí mismo») (Oakeshott, 2009f, 37).

Si no hay esencia o teleología que oriente el desarrollo, la persona es un espacio de múltiples posibles realizaciones, y estas realizaciones se despliegan al ritmo de las interpretaciones que uno da sobre otros, sobre el mundo y sobre sí mismo. De este modo, Oakeshott cree estar defendiendo un potencial de desarrollo mucho más amplio y plástico que el que proponen las visiones esencialistas. Claro está, que esta plasticidad no es infinita:

La autorrealización para los seres humanos no es la realización de un fin predeterminado de manera exacta que sólo necesita circunstancias favorables para ser alcanzado; pero este individuo tampoco es una posibilidad infinita y desconocida que una herencia de logros humanos pueda, de igual manera, frustrar o promover. Los individuos no son abstracciones racionales, son personalidades históricas, son parte de los componentes de este mundo de logros humanos (Oakeshott, 2009d, 73).

No debemos interpretar de modo estrecho el alcance de la comprensión a que se refiere Oakeshott. No se trata de una acción primera y necesariamente teórica, reflexiva: "Una vida humana está compuesta de prácticas humanas, y cada práctica es una revelación de lo que un hombre cree sobre sí mismo y sobre el mundo» (Oakeshott, 2009e, 94). Es en las prácticas que se pone al descubierto de manera más o menos implícita la comprensión que la persona tiene de sí misma y de los demás. Así, «una práctica puede ser reconocida perfectamente como un lenguaje de auto-revelación que puede ser hablado sólo por los agentes» (Oakeshott, 2009f, 58).

En la educación de esta fuerza constitutiva que Oakeshott atribuye a la interpretación y la autocomprensión radica la esencia de la libertad: "Esta libertad inherente al ser humano radica no sólo en su capacidad de elaborar enunciados que manifiestan su comprensión de sí mismo, sino también en el hecho de que el mundo sea para él lo que él comprende que es, y que él sea lo que él mismo comprende que es. Un ser humano es libre no por poseer libre albedrío sino por ser en sí mismo lo que él es para sí mismo» (Oakeshott, 2009f, 38). De este modo, la actividad de la racionalidad deviene dialécticamente, y se despliega en la medida en que alcanza la autorreflexividad.

Estos principios tienen una notable incidencia en el campo educativo. Que la persona se constituya en su autointerpretación significa que ninguno de nosotros nace humano; que "cada uno es lo que aprende a ser» (Oakeshott, 2009f, 40). Esto es así porque la realidad «está compuesta de estados mentales de los que, dado que constituyen interpretaciones, sólo se puede gozar en virtud de que se los comprenda" (Oakeshott, 2009e, 97). De lo que se deduce que el aprendizaje es también nota distintiva del ser humano y que la libertad humana (entendida como condición 
trascendental) se realiza en virtud del aprendizaje. Con la educación, el sujeto amplía su universo de significados, y amplifica así sus alternativas de desarrollo potencial (Oakeshott, 2009f, 70). Todo esto viene implicado en el concepto de homo dissens:

El compromiso educativo es necesario porque nadie nace siendo un ser humano, y porque la cualidad de ser humano no es una potencia que se actualiza mediante un proceso de «desarrollo». El recién llegado humano no es un organismo que busca adaptarse a circunstancias que favorezcan su subsistencia; es un homo dissens, una criatura capaz de aprender a pensar, a comprender y a representarse a sí mismo en un mundo de representaciones humanas y, de esa manera, adquirir un carácter humano (Oakeshott, 2009e, 96).

Cada hombre ha de adquirir la «capacidad de arrojar al mundo su propia versión de un ser humano mediante un comportamiento que es a la vez una revelación y una representación de sí mismo» (Oakeshott, 2009e, 97-98).

\subsection{La importancia de la conversación}

Es en virtud de la aplicación de estos principios que Oakeshott propone su metáfora de la conversación para aludir a la esencia de la educación en general, y la educación superior en particular. El conocimiento que se imparte en las universidades no ha de apuntar a proveer información confiable sobre la naturaleza humana (Oakeshott, 2009f, 49). Antes bien, y en línea con lo ya dicho, debe proveer acceso a la cultura.

Una cultura, en especial una como la nuestra, es una continuidad de sentimientos, percepciones, ideas, compromisos y actitudes, entre otros, que tiran en distintas direcciones, que con frecuencia se critican entre sí y que no se relacionan de manera contingente para componer una doctrina, sino para componer lo que llamaré un encuentro conversacional (Oakeshott, 2009f, 50).

La cultura es esa herencia a la que se hiciera referencia anteriormente. Sus componentes son voces (expresiones de interpretaciones bien definidas y condicionales del mundo en un idioma también definido de autocomprensión humana) que están unidas en una conversación (Oakeshott, 2009f, 62). Estas voces repican de muchas maneras, y ofrecen distintos relatos. Las voces no se identifican exclusivamente con palabras dichas. Comprenden también una reunión de diversas actividades humanas, una reunión de varios modos de la imaginación (Oakeshott, 2000d, 455) ${ }^{7}$. No todas estas expresiones son igualmente importantes, pero todas merecen su espacio en la armonía del concierto de voces universal.

Al entablar esta conversación, la actividad educativa pretende indagar acerca de las «aventuras de la autocomprensión humana»: aquellas indagaciones, acciones

7. Cf. también OAKESHOTT, 2009c. 
y enunciados concretos en los que los seres humanos expresaron su comprensión de la condición humana (Oakeshott, 2009f, 48). El aprendizaje se concibe, entonces, como la acción de «llegar a comprender los indicios de una vida humana manifestada en una cultura histórica de notable esplendor y lucidez y con ser invitado a reconocerse uno mismo en términos de esa cultura". En otras palabras, "consiste en aprender a responder a las invitaciones de estas grandes aventuras intelectuales en las que los seres humanos han llegado a presentar distintas interpretaciones del mundo y de sí mismos» (Oakeshott, 2009f, 51-54).

En definitiva, sólo existe aprendizaje cuando el alumno logra ser interpelado por una "aventura" que forma parte de un legado histórico y cuando se reconoce en ella. "El ser humano no tiene una mejor manera de lograr lo mejor de sí que aprendiendo a reconocerse en el espacio de esa herencia» (Oakeshott, 2009d, 73). Se logra de este modo una cierta identificación entre lo ocurrido tal vez hace años a otras personas o comunidades y lo que ocurre al propio sujeto en su particular realidad actual. La aventura puede revestir distintos modos y no debe concebírsela con estrechez: puede tratarse de un descubrimiento científico, un relato histórico, un emprendimiento social, una actividad artística, literaria, de danza, pintura, canto, una actividad deportiva, etc.

Como hemos visto, se derivan dos consecuencias inmediatas de este acto de identificación. En primer término, el aprendizaje por identificación permite la mencionada ampliación de la mente al promover la extensión de la capacidad de aprender. En términos de Oakeshott, «iniciar a un alumno en el mundo de los logros humanos es hacer que acceda a muchas cosas que no existen en su mundo» (Oakeshott, 2009d, 72-3). En segundo término, esta ampliación se orienta hacia la autorrealización. En efecto, este acto de interpelación activa permite identificar distintas posibles versiones alternativas de lo humano, y orienta a sintonizar con alguna en particular para ir conformando la propia y original versión. Este es el objeto propio de la educación, si cabe hablar de objeto en este campo.

No puede decirse que esta transacción entre generaciones tenga un «objetivo» o "propósito" extrínseco: para el maestro es parte de su compromiso de ser humano; para el sujeto de aprendizaje es el compromiso de llegar a ser humano [...] Cuando participan en esta transacción, cada uno se hace cargo de guardar una parte pequeña o grande de la herencia de interpretaciones humanas. Éste es el espejo frente al cual cada uno representa su propia versión de la vida humana, emancipado de las meras opiniones de la moda (Oakeshott, 2009e, 102).

En suma, la educación, como actividad de conversación, procura aportar más calidad de vida al introducir a la persona en aventuras de comprensión nuevas. «No hay diferencia entre un alumno que accede a su herencia de logros humanos y un alumno que logra lo mejor de sí» (Oakeshott, 2009e, 103). En el diálogo tiene lugar una ampliación del propio horizonte a través de la asimilación o identificación con una nueva interpretación sobre las cosas. La condición humana adquiere, así, 
condición histórica y narrativa: cada ser humano se convierte, de algún modo, en su propia historia (Oakeshott, 2009f, 40).

En virtud de lo expuesto, Oakeshott prefiere hablar de "capital» al referirse al legado educativo, en tanto y en cuanto 1) sólo se disfruta en su uso, 2) resulta de un préstamo cuyos usos no son inmediatamente evidentes, 3) se reinvierte automáticamente en la capacidad de aprender (Oakeshott, 2000e, 181).

\subsection{Notas de la educación}

La educación liberal habrá de ser generalista: estará abierta a los distintos modos que conforman la herencia humana. La práctica educativa exigirá un alejamiento del hic et nunc, de las necesidades del momento cultural o industrial vigente, y tendrá estándares propios, ajenos al contexto. Constituirá una cierta liberación.

Pero ello no debe inducir a confusión. La educación no puede ser concebida como una tarea esencialmente transformadora. Es una actividad más bien conservadora (Oakeshott, 2009b), sin que quepa otorgar a este concepto una connotación negativa. Para Oakeshott, la educación es y debe ser esencialmente conservadora porque su principal misión reside en rescatar de la herencia cultural -vale decir, del legado histórico de aventuras pasadas y presentes- aquellos elementos que pueden enriquecer y ensanchar el mundo de significados del estudiante. Al educador no le toca crear nuevos mundos de pensamiento. Puede hacerlo, si posee la genialidad suficiente. Pero no lo hará en calidad de educador sino de poeta, de investigador, de escritor, de filósofo, de emprendedor. Al educador le toca crear un «flujo de simpatía» entre el legado cultural recibido y las nuevas generaciones permeables a su recepción.

Por otra parte, si la educación es conversación e implica un rescate conservador de la herencia, la inexistencia de maestros es impensable en el modelo educativo de Oakeshott. El alumno aprende sólo si el maestro enseña. La enseñanza «es la iniciación deliberada e intencional de un alumno en el mundo de los logros humanos, o en una parte de ese mundo» (Oakeshott, 2009d, 71). La tarea del maestro consiste en seleccionar, organizar, secuenciar, planificar tareas (Oakeshott, 2009d). Es un gran conversador, cuyo principal desafío consiste en generar aquel flujo de simpatía. Las máquinas no necesariamente tienen esta capacidad. Sus criterios de selección y ordenamiento son rígidos y parametrizados, se les escurre la riqueza que sólo la capacidad interpretativa humana logra entrever. Tampoco poseen "capacidad simpatética». No vibran emocionalmente con aquella aventura que rescatan. De allí que Oakeshott rescate la necesidad de ejemplaridad del maestro (Oakeshott, 2009d) no tanto por la dimensión moral que compromete su tarea, sino porque éste logra despertar simpatía fundamentalmente en torno a aquello que a él mismo le ha resultado atractivo.

Lo dicho sobre la educación en general vale especialmente para el nivel universitario. Para ilustrar este hecho, Oakeshott recurre a la distinción entre 
educación vocacional y educación universitaria (Oakeshott, 2000e, 183). La educación vocacional refiere a la adquisición de habilidades. Es muy especializada no sólo porque implica concentrarse en una habilidad exclusiva (construcción de edificaciones), sino porque atiende a la adquisición de conocimientos ya existentes (la literatura) y la habilidad para aplicarlos. La educación universitaria, en cambio, implica formación en lenguajes, no sólo en literaturas. Se interesa en el uso y manejo de modos de pensamiento (Oakeshott, 2000e, 185). El profesor universitario tiene que impartir una familiaridad con los modos de pensamiento del capital intelectual de una civilización (Oakeshott, 2000e, 188).

Por ello, la educación universitaria ha de estar centrada en grandes textos, que remitan a grandes aventuras del pensamiento. No debe favorecerse una aproximación ideológica a estos textos o tratárselos reverencialmente como objeto de museo. La importancia de su lectura radica en que permiten cumplir con el cometido último de la educación: que el alumno comprenda las insinuaciones de una vida humana dispuesta en una cultura histórica determinada. En su tarea, el profesor habrá de contagiar su propia simpatía a los alumnos que desconocen la aventura en cuestión. Un profesor poco propenso a simpatizar con lo que enseña está condenado al fracaso y sus alumnos serán objeto de una verdadera estafa educativa. También el docente que imparte mera información pervierte el aspecto principal de su legado: la formación en el discernimiento (Oakeshott, 2009d, 72). En efecto, la herencia de logros humanos en la que el maestro debe iniciar a su alumno es el conocimiento. Pero «hay que reconocer el conocimiento como conjunto de capacidades, en cada una de las cuales hay una síntesis de información y de discernimiento" (Oakeshott, 2009d, 83).

\section{ANÁLISIS CRÍTICO DE LA FILOSOFÍA EDUCATIVA DE OAKESHOTT}

Hasta el momento, sólo se ha avanzado en la descripción de la propuesta educativa de Oakeshott en vistas a mostrar en qué medida sus ideas acerca de la educación guardan relación con los principios generales que iluminan el conjunto de su producción intelectual.

\subsection{Análisis de factibilidad}

Llegados a este punto, es posible iniciar una reflexión crítica que aporte juicios de valor respecto de esta propuesta. Lo más sencillo y, al mismo tiempo, más complejo refiere al análisis de su factibilidad, consistente en evaluar en qué medida las intuiciones de Oakeshott pueden conformar un modelo de enseñanza aplicable para la educación superior latinoamericana en el siglo XXI. Cualquier análisis de factibilidad constituye, por fuerza, una cierta extrapolación que amenaza con convertirse en inconducente si se atiende precisamente al énfasis puesto por el 
autor de privilegiar el carácter «situado» de toda experiencia cognitiva ${ }^{8}$. La tarea, sin embargo, no es vana y su sentido último podrá advertirse una vez que alcancemos las conclusiones del presente trabajo.

Es evidente que muchas de las propuestas educativas de Oakeshott parecen conducir en dirección contraria a la que se indican en diversos círculos de intelectuales y, fundamentalmente, a las políticas vigentes en diversos países ${ }^{9}$. Las diferencias se revelan profundas, en tanto y en cuanto refieren a una discusión sobre los fines mismos de la educación superior. Nos concentraremos particularmente en dos de ellas.

En primer lugar, Oakeshott concibe la educación universitaria como una actividad tendiente a evadirse del bic et nunc, con el objetivo principal de introducir al estudiante en la herencia de conversaciones que constituyen el capital cultural. Este cometido abarca la iniciación en nuevos lenguajes, introductorios a las aventuras de pensamiento que más aportan al despliegue de la potencialidad de los estudiantes. Promueve la conversación en torno a información que trae consigo un discernimiento y cuyo principal objeto es la adquisición del discernimiento mismo. Alienta la inmersión en un flujo de simpatía que permite apreciar, antes que fórmulas vacías, la riqueza intelectiva y afectiva del mundo del pensamiento, un mundo que abre horizontes y promueve una mejor versión acerca de nosotros mismos.

Oakeshott no descarta otros fines en la educación de los jóvenes y apela a la ya mencionada distinción entre educación vocacional y educación universitaria para darles su legítimo espacio. Pero enfatiza la necesidad de que la Universidad no se disperse abocándose a la primera ${ }^{10}$. Naturalmente, esto conlleva un distanciamiento de la universidad respecto de las necesidades de su entorno.

8. La enseñanza mediante conversaciones constituye la esencia del sistema inglés oxoniense y cantabrigense, con su sistema de Colleges (recuérdese que Oakeshott fue fellow del Caius College de Cambridge). Sin embargo, Williams (2007, 6-7. 49) advierte que -en sus referencias al sistema educativo- Oakeshott tiene en mente también el pensamiento pedagógico hegeliano y, en la práctica, la política educativa de la Francia decimonónica con el sistema de Académies. Ya se han reseñado también la afinidad entre su propuesta y la de modelos de la schôlé del s. XIII, y la correspondencia que Fuller encuentra entre su pensamiento y el de Newman (Fuller, 2003). Según este autor, algunos aspectos de la educación liberal de Oakeshott hunden sus raíces en intuiciones recogidas por la escolástica de la tradición griega clásica. Sin embargo, debe relativizarse la imagen estereotipada que la tradición nos ha legado sobre las primeras universidades del siglo xiII. Haskins advierte hasta qué punto estas primeras universidades, principalmente la de Bolonia, surgieron especialmente como ámbitos orientados a la formación profesional, con un fuerte sentido utilitario en el que predominaron los criterios del alumnado en la definición de los estilos y modos de intercambio de conocimiento (Haskins, 2012).

9. No se ofrecerá aquí una reseña de obras que refieran a la situación de la educación superior latinoamericana. Una aspiración semejante excede las pretensiones de este artículo y ameritaría un tratamiento imposible de cubrir en tan pocas páginas. Con independencia de referencias bibliográficas, el lector latinoamericano sabrá en qué medida le resultan familiares los aspectos del diagnóstico que aquí se sintetiza. Para una síntesis de las principales problemáticas vigentes, se sugiere la lectura del prólogo a la edición en español de la obra de AltBach, Educación superior comparada, de 2009.

10. Es preciso advertir que al plantear su distinción entre educación vocacional y educación universitaria en 1967 Oakeshott se esfuerza por presentar algún matiz. En su opinión, los estudiantes 
Lo cierto es que la discusión en torno a modelos universitarios vigente desde hace algunos años da cuenta de la importancia y necesidad de su integración con la sociedad. Se aspira al desarrollo de vinculaciones que alejen a la universidad del solipsismo y la autorreferencialidad para dotarla de una mayor capacidad de dar respuesta a las necesidades circundantes (Gibbons, 1997; Vera, 2003; Garrido, 2013; Brunner, 2014). Fruto de este esfuerzo de articulación, surge una tendencia creciente de implementar carreras cortas y especializadas. Esta situación se ve extremada por las exigencias de los organismos de acreditación de los gobiernos, que en muchos casos imponen criterios y diseños orientados a la especialización extrema, sin que queden resquicios para el desarrollo de planes de formación más abiertos. En este marco, la incorporación de asignaturas que contribuyan a la ampliación del pensamiento constituye una utopía deseable para algunos, pero lejana en sus posibilidades de concreción.

La segunda diferencia refiere a la teoría del intervalo también mencionada. Se trata indudablemente del aspecto más controvertido de su propuesta educativa:

El alejamiento del mundo inmediato y local del estudiante, de las preocupaciones del momento de ese mundo [...] éste es el significado de la palabra scholế -y no «tiempo libre» ni «ocio»- [...] La «Escuela» es una emancipación que se logra con un continuo redireccionamiento de la atención. Aquí, al estudiante no lo motivan sus propias preocupaciones, sino insinuaciones de excelencia y aspiraciones con las que jamás ha soñado todavía [...] La "Escuela» es «monástica» en el sentido de que se trata de un espacio apartado en el que pueden oírse eminencias en distintas áreas porque el barullo provocado por la despreocupación y las parcialidades mundanas no se oye, o se oye muy bajo (Oakeshott, 2009e, 100-101).

Esta premisa se contrapone fuertemente con la tendencia que orienta el sistema superior latinoamericano de lograr de mayores niveles de inclusión dentro de las universidades, como prerrogativa de equidad y justicia social (Teodoro, 2014). Esto obliga a aceptar una diversificación de perfiles en los estudiantes. Así, mientras que la teoría de Oakeshott parece ser consistente con un diseño social determinado, que relega la educación superior universitaria a un reducto social específico, la tendencia actual aspira a facilitar el ingreso, permanencia y graduación de todo el espectro, como garantía de equidad e igualdad de oportunidades no sólo profesionales, sino también personales. A estas dificultades de orden político-normativo pueden añadirse otras de orden práctico (muchas cuales se derivan del primer

que están aprendiendo una aptitud vocacional pueden reconocer que la literatura que están utilizando es el «resultado de empresas destinadas a ampliar nuestro entendimiento acerca de nosotros mismos y del mundo" (OAKESHOTT, 1967, 136). La incorporación de semejante matiz no necesariamente permite superar la tensión señalada. Evidentemente, el pensamiento de Oakeshott sigue anclado en una dialéctica que no reconoce la ineludible presencia de la formación en lenguajes que subyace a la formación vocacional (Williams, 2009), lo que constituye uno de los aspectos más críticos de su pensamiento, de cara a los desafíos de la educación del siglo xxi. 
orden), que no estamos en condiciones de analizar aquí, pero que fácilmente podrán identificarse ${ }^{11}$.

A pesar de hallarse en un contexto muy diferente al actual, Oakeshott no fue ajeno a la consideración de críticas de naturaleza semejante. Sin embargo, no se mostró proclive a armonizarlas; antes bien, procuró denunciarlas. Una de sus últimas obras, "Un espacio de aprendizaje», de 1975, advierte claramente sobre los tres "autoengaños» que -según su entender- se cernían sobre la educación superior de fines del siglo xx: la aspiración a la modernidad (la afición por estar «a la altura de los tiempos»), la amenaza de la socialización, y la incomprensión sobre lo que significa educación general (Oakeshott, 2009f, 56).

En su opinión, si bien la actividad universitaria está indefectiblemente asociada a su contexto (como toda actividad humana), no debe pervertirse su lugar propio. Por ello, ante una cultura que impone ciertos criterios que pueden ser limitantes y empobrecedores de la experiencia humana, es la universidad la única organización que puede actuar como faro preventivo. En términos del mismo Oakeshott, la universidad debe poseer "cualidad homeopática", vale decir, capacidad autorregenerativa que le permita curarse de los mismos males que la aquejan. Ninguna otra organización debe poseer esta capacidad del modo en que la universidad lo necesita. Su denuncia constituye, en su opinión, un antídoto contra el avance de ciertas prácticas que pervierten la educación superior, alejándola de su cometido principal.

Para quienes comparten la visión oakeshottiana, la situación actual podría revelarse ingrata y desafiante. Los más optimistas intentarán promover a toda costa algunas prácticas de inspiración liberal que han probado ser beneficiosas para el logro del ideal educativo descripto: a) la enseñanza a través de grandes textos (Great Books) que constituyan "aventuras del pensamiento»; b) la incorporación en las estructuras curriculares de asignaturas que contribuyan al desarrollo de otros lenguajes distintos del de la pura especialización, y que dialoguen -desde otro lenguaje- con la especialidad; c) la aspiración a promover la dedicación plena a los estudios, de manera limitada en la medida de las posibilidades de los alumnos; d) la revitalización del lugar del profesor, que debe considerarse factor irreemplazable

11. La teoría educativa de Oakeshott podría ser confrontada, por ejemplo, con las deficiencias de formación de base que existen en muchos alumnos que acceden a la educación superior, así como las deficiencias en los docentes encargados de brindar dicha educación. Asimismo, su teoría del intervalo resulta difícilmente aplicable en el contexto de una creciente incorporación de alumnos que aspiran a compatibilizar - por necesidad o por opción- la actividad laboral con la formación universitaria. Este hecho, sumado a las deficiencias de base mencionadas, genera que el tiempo de graduación se dilate mucho más allá de lo que los diseños teóricos indican. En cuanto a la actividad del docente, la conversación pausada y liberal (en el sentido de desligada a las exigencias y obligaciones del bic et nunc) que Oakeshott atribuye a la actividad superior universitaria parece ser difícilmente conciliable con las exigencias que se imponen hoy en la vida académica. La producción de papers, la asistencia a congresos, la dirección de tesis, el dictado de cursos sobrecargan una agenda en la que existe cada vez menos espacio para el pausado intercambio que Oakeshott describe en sus escritos. La gratuidad de la conversación se confronta, así, con una cierta mercantilización de la vida académica. 
incluso en el contexto de la urgente necesidad de introducir nuevas tecnologías; e) la necesidad de contar con maestros que simpaticen (en el sentido profundo del término) con aquello que enseñan; f) la promoción de espacios de conversación no sólo temporales, sino físicos, en tiempos en que los docentes y alumnos padecen la agitación propia de la civilización contemporánea, y que no se reduzcan al mero intercambio informal.

La incorporación de estas prácticas no resulta en absoluto sencilla por razones de diversa índole. Habrá quienes, incluso simpatizando con estas prácticas, y no necesariamente por adherir a los planteamientos de Oakeshott, se muestren desconfiados respecto del grado de éxito de su aplicación. Es evidente que hay algo de extremo en los planteamientos de Oakeshott, algo de "quijotesco» (por referirnos a un personaje que este autor tanto admiraba). En el siguiente apartado analizaremos en qué medida este carácter extremo resulta coherente con los principios filosóficos que inspiran su obra.

\subsection{Análisis de coherencia}

El análisis de coherencia pretende indagar si existe suficiente consistencia entre sus propuestas educativas y los principios filosóficos en los que estas descansan. Es en este punto que surgen los principales desafíos de la teoría educativa de Oakeshott.

Ya se ha dicho que, para Oakeshott, la universidad es y debe ser conservadora. También se ha dicho que la transformación no está descartada en su pensamiento y que es posible operar cambios en la tradición cultural, incluyendo en ella a la tradición de la educación superior. Oakeshott busca evitar explícitamente que lo acusen de "quietismo", aunque se muestra partidario de los cambios pequeños y lentos, antes que de los grandes y abruptos (Oakeshott, 2000f, 378). En su opinión, el cambio es en alguna medida saludable y necesario, porque permite el crecimiento individual y social. Desde este punto de vista, Plotica tiene razón al relativizar la caracterización de Oakeshott como pensador "conservador" (Plotica, 2013). Indudablemente, privilegia el talante conservador sobre el reformista por razones filosóficas. Pero, en su interpretación, el conservadurismo no se opone al cambio. Antes bien, lo hace posible, en la medida en que las nuevas insinuaciones, voces y aventuras reformistas surgen a partir de una herencia efervescente de sentido y riqueza.

Ahora bien, Oakeshott parece presuponer que -en el campo de la educaciónexisten cambios que son perfectivos, a la par de otros que son degenerativos. En otras palabras, algunos contribuyen a gestar una mejor humanidad, más plena y variada, y otros a limitarla o pervertirla. La sola existencia de «autoengaños» es indicativa del reconocimiento de lo inverso, vale decir, de desarrollos genuinos.

En este contexto, ¿cuál es el criterio que permite distinguir un autoengaño de un desarrollo genuino? Concentrémonos por un momento en las transformaciones que aquejan al sistema superior, en particular, en la tendencia a la creciente 
especialización y el imperativo de la inclusión. ¿¿Son estas transformaciones graduales? Así parece. En ocasiones, acontecen sin que los educadores nos demos cuenta siquiera. Ocurren en tanto y en cuanto, a través de prácticas concretas que se instalan progresivamente, se pone de manifiesto una nueva interpretación sobre lo que es educar. Cuando un profesor indica que las artes liberales ya no tienen cabida en el currículum, o cuando un directivo elimina de cuajo toda aquello que no se corresponde con la especialidad en un plan de formación, en cada uno de estos actos concretos se expresa una determinada visión sobre la educación. A Oakeshott le preocupa el advenimiento de este tipo de transformaciones. Sin embargo, ¿sobre qué bases sostiene y legitima su preocupación?

Evidentemente, los criterios para discernir desarrollos genuinos de autoengaños no pueden provenir de la visión de esencias en la medida en que se ha descartado todo género de teleología. Recordemos que para Oakeshott todo es historia, es narrativa y no cabe acudir a criterios extrínsecos al devenir para evaluar dicho devenir (Oakeshott, 2009f).

Al mismo tiempo, el rechazo del esencialismo no implica la aceptación de un nihilismo o relativismo vacío de referencias (lo que invalidaría cualquier posibilidad de distinguir engaños y desarrollos genuinos), o de un formalismo que confía en la suficiencia de la razón para construir acuerdos transhistóricos. Su pensamiento parece alejarse de una concepción de la historia como mera linealidad fáctica de contingencias, para reconocer en ese mismo entramado de contingencias un cierto caudal de experiencias y autointerpretaciones que, surgidas de ese mismo devenir por medio de «insinuaciones» que operan en la tradición misma (Baqués, 2014, 30), actúan como «ideales» (O'Sullivan, 2002, 72) y se convierten en "criterios de discernimiento» (Smith, 1996, 603). La mecánica de esta evolución es, por tanto, «incrementalista antes que racionalista» (Baqués, 2014, 31).

De este modo, la antropología de Oakeshott se configura en torno a la vivencia, aceptación y teorización de variables inherentes a la condición humana general que, siendo históricas y situadas en su despliegue, actúan al mismo tiempo como condiciones de posibilidad de dicho despliegue y conquistas de la autocomprensión histórica. Lo cierto es que, en la obra de Oakeshott, estas variables no están reconocidas explícitamente como tales, lo que constituye una insuficiencia o sobreeconomía de conceptos, como algunos autores convienen en señalar a partir del análisis de diversos aspectos de su pensamiento (Auspitz, 1976; Williams, 2002). Sólo en On Human Conduct Oakeshott nos ofrece una descripción de algunos de estos criterios, que son presentados como "postulados de la conducta" (Oakeshott, 1975, 36 y ss.). Luego de caracterizarlos, concluye:

Lo que he llamado postulados de la conducta -consciencia reflexiva, comprensión, deliberación, elección gobernada por restricciones de las prácticas, etc.- no son "Contingencias" [goings-on] que puedan o no preceder a las acciones o declaraciones y que puedan estar tanto comprometidas de manera consciente como estar ausentes; son las condiciones de la conducta (Oakeshott, 1975, 89). 
¿Cuáles son algunas de estas condiciones o criterios en Oakeshott? La consideración de la libertad como disponibilidad situada; la asunción del principio de la autocomprensión como definitorio de la persona; la condición narrativa, que acoge el valor de la interpretación constitutiva y reconoce su devenir en el tiempo; en consecuencia, el carácter histórico del sujeto; la ineludible necesidad del aprendizaje para el desarrollo subjetivo, que nos abre a nuevos lenguajes que transforman nuestro mundo y nuestro "yo»; la asimilación del mundo humano como mundo de significados, un mundo que recibe el nombre de "cultura" y que se conforma como resultado de un acto interpretativo; etc. Todos estos elementos son condición para el devenir del sujeto, y al mismo tiempo criterios para identificar actividades más o menos propensas a favorecer el despliegue humano.

En este sentido, la visión antropológica de Oakeshott puede inscribirse en la nómina de autores contemporáneos que, sin asumir una visión metafísica, postulan la existencia de ciertas "condiciones trascendentales" (Bellomo, 2011, 360-363) que explican y sostienen el carácter narrativo de la identidad personal y colectiva. Dichas condiciones habilitan el análisis de los procesos sociales en términos de su evolución o involución, en una acepción que puede caracterizarse como "corregibilidad relativa", aun en contextos en que se reafirma la contingencia no teleológica del devenir y la insuficiencia de epistemologías fundacionalistas y racionalistas (Bellomo, 2009, 80) ${ }^{12}$.

Los criterios para realizar este discernimiento parecen surgir de lo que Timothy Fuller, discípulo de Oakeshott, reconoce como «verdades perennes»:

A pesar de que no era propenso a usar ciertos términos como "verdades perennes», veía con claridad que existen determinadas formas en las que, como le gustaba decirlo, los seres humanos pueden interpretarse y malinterpretarse a sí mismos. Las personas instruidas aprenden a reconocer esto en todas las formas en las que se les presenta (Fuller, 2000, 10-11).

\section{CONClusión}

La identificación de los autoengaños de la educación, así como la posibilidad de que el ser humano se "malinterprete a sí mismo» en su autocomprensión, sólo se explican en la medida en que se reconoce la existencia de condiciones de la conducta que actúan de criterios de discernimiento. La educación está llamada a preservar y desplegar estas condiciones en beneficio del desarrollo individual y social. Si no lo hace, se pervierte, y su perversión significa el deterioro de lo humano.

12. En la obra de Charles Taylor puede advertirse un reconocimiento semejante de "condiciones trascendentales» que subyacen y explican el devenir, sin estar sujetas ellas mismas al devenir (BELLOMO, 2011), aunque es sabido que la obra de Taylor no ha sido inspirada particularmente por las intuiciones oakeshottianas. 
Pero este discernimiento de engaños y malinterpretaciones se realiza no sólo a la luz de estos criterios, sino también en el marco del necesario equilibrio que opera entre lo que él describe como la "política de la fe» y la "política del escepticismo». Si bien Oakeshott formula esta distinción para contribuir al análisis de la actividad política, es lícito vincularla con otros procesos sociales. De hecho, si se admiten versiones religiosas y económicas (Oakeshott, 1998, 89), no parece haber impedimento para su aplicación en el campo educativo.

Sabemos que la fe y el escepticismo constituyen dos polos teóricos, abstractos, a los que se llega por teorización, y que el devenir social se compone habitualmente de una mezcla de ellos (Oakeshott, 1998, 44-46). La política de la fe confía en la capacidad de los sistemas racionales e instituciones para introducir cambios perfectivos en aras de la mejora planificada (Oakeshott, 1998, 51). Aspira al logro de condiciones ideales. En la educación superior contemporánea, la aspiración al logro de mayores niveles de inclusión o especialización educativa bien podría encuadrarse en esta inspiración.

La política del escepticismo apela con modestia a la sabiduría del conocimiento y las prácticas heredadas y desconfía del poder de las instituciones para lograr la ansiada transformación. Reconoce la necesidad de las políticas y acciones del Gobierno, pero no les otorga poder salvífico (Oakeshott, 1998, 58). Más bien aspira a limitar su esfera de incumbencia para que la instancia de gobierno actúe lo estrictamente necesario, limitándose su rango de acción como debe limitarse el ajo en las comidas (Oakeshott, 1998, 65). Esto implica potenciar la autonomía de las instituciones mediante la presentación de un marco de posibilidades siempre creciente y diversificado. En su aplicación educativa, esta inspiración desconfía de las transformaciones orgánicas que extremen la importancia de responder a las necesidades del mercado o absoluticen el desarrollo de procesos inclusivos.

Así, mientras que la primera de las lógicas es reformista, la segunda se presenta naturalmente como conservadora. La convivencia de movimientos conservadores y progresistas conduce a la consolidación de una instancia "media" (Oakeshott, 1998, 161), justificando la existencia de modelos «híbridos» (Baqués, 2014, 27). Cabe preguntarse cuál es la lógica preponderante en el modelo educativo superior de Oakeshott. A primera vista, resulta claro que la lógica escéptica asume un indiscutible protagonismo.

Este celo antirreformista explica las resistencias de los defensores de la educación liberal oakeshottiana de acogerse a las nuevas tendencias de la educación superior. Las dificultades de aplicación de este modelo educativo resultarán para ellos indicativas del nivel de deterioro al que ha llegado la educación superior. Pero este mismo celo, si resulta extremo, puede poner en evidencia cierta estrechez en la caracterización e interpretación de lo que implica la "educación liberal», con los criterios de discernimiento que habitualmente se asocian con ella. Cabe preguntarse si esta última valoración no es más acorde con la inspiración de la educación liberal de Oakeshott. 
La conclusión del presente artículo es que las dificultades de aplicación del modelo liberal oakeshottiano reconocidas en el análisis de factibilidad no responden exclusivamente a la exacerbación de ciertos postulados "progresistas» en el ámbito de la educación (que parecen inspirarse en la política de la fe y apostar a ideales que se han erigido en "absolutos»), sino también a la consideración algo estrecha de los supuestos antropológicos que inspiran los fines de su modelo educativo y actúan -orientados por una política del escepticismo también absolutizada- como criterios expulsivos al momento de valorar las tendencias vigentes. En este marco, resulta lícito promover un esfuerzo en el seno de la educación liberal para dejarse interpelar por las nuevas «aventuras del pensamiento» que afloran en el contexto educativo.

El esfuerzo inverso también será, por tanto, igualmente fructífero: desde una tradición refractaria al espíritu liberal, será posible considerar con nuevos ojos la propuesta educativa de Oakeshott. Su mensaje, en apariencia extemporáneo e ingenuo, adquirirá la capacidad de iluminar y, quién sabe, acaso generar cambios que contribuyan al logro de un modelo educativo más atento al cometido central de la educación superior, menos confiado en el carácter mesiánico que adquieren -en ocasiones- los sistemas y políticas del gobierno educativo, más permeable a reconocer la complejidad y multidimensionalidad de la tarea docente y, al mismo tiempo, más proclive a la instauración de un modelo educativo más autónomo y "modesto", que no resigne ideales pero reconozca la ineludible tensión que opera en los sistemas educativos.

La vigencia del pensamiento de Oakeshott revelará, así, su mayor fecundidad, en tanto que permitirá no sólo la revisión de las prácticas y políticas vigentes a la luz del carácter "homeopático" de la tradición universitaria, sino también la renovación profunda del sentido mismo de lo que significa la educación superior.

\section{REFERENCIAS BIBLIOGRÁFICAS}

Altbach, P. (2009) Educación superior comparada. El conocimiento, la Universidad y el desarrollo. Buenos Aires, Fundación Universidad de Palermo.

Auspitz, J. (1976) Individuality, Civility and Theory: The Philosophical Imagination of Michael Oakeshott. Political Theory, 4, 261-294.

AuspiTz, J. (2014) A New Look at Michael Oakeshott. Claremont Review of Books, Spring 2014, 54-59.

BAQUÉs, J. (2014) La obra de Michael Oakeshott como paradigma del liberalismo conservador. Revista Española de Investigaciones Sociológicas, n. ${ }^{\circ}$ 145, 25-42.

Bellomo, S. (2009) Reflexiones en torno a la tesis de la «incorregibilidad» cultural. Themata. Revista de Filosofía, 41, 77-96.

Bellomo, S. (2011) Lenguaje, verdad, libertad: el realismo expresivo de Charles Taylor. Pamplona, EUNSA.

BRunNer, J. J. (2014) La idea de la Universidad pública en América Latina: narraciones en escenarios divergentes. Educación XXI, febrero, 17-34. 
CARr, D. (2008) Book Review: Education and the Voice of Michael Oakeshott. Journal of Philosophy of Education, 42 (2), 345-347.

FulLER, T. (2000) Introducción: una comprensión filosófica de la educación, en La voz del aprendizaje liberal. Madrid, Katz/Liberty Fund, 7-13.

Fuller, T. (2003) The Idea of the University in Newman, Oakeshott, and Strauss. Academic Questions, Winter 2003-2004, 37-53.

GARRIDO, C. (2013) Innovación, vinculación universidad-empresa y desarrollo. Universidades, n. ${ }^{\circ} 58,6-23$.

GibBons, M. (1997) La Nueva producción del conocimiento: la dinámica de la ciencia y la investigación en las sociedades contemporáneas. Barcelona, Pomares-Corredor.

Grant, R. (1990) Oakeshott. Thinkers of our Time. London, Claridge Press.

Haskins, C. H. (2013) El surgimiento de las universidades. Buenos Aires, Universidad de Palermo.

Newman, J. H. (1973) The Idea of a University. Yale, Yale University Press.

O'Sullivan, N. (2002) Why Read Oakeshott? Society, March/April 2002, 71-74.

Oakeshott, M. (1933) Experience and its Modes. Cambridge, Cambridge University Press.

OAKeshotT, M. (1975) On Human Conduct. Oxford, Clarendon Press.

Oakeshott, M. (1998) The Politics of Faith and the Politics of Scepticism. New Haven, Yale University Press.

OAKESHOTt, M. (2000) La conducta racional, en El racionalismo en la politica y otros ensayos. México, FCE, 103-131.

OAKeshotT, M. (2000a) El racionalismo en política, en El racionalismo en la política y otros ensayos. México, FCE, 21-53.

OAKeshott, M. (2000b) El concepto de universidad, en La voz del aprendizaje liberal. Madrid, Katz/Liberty Fund, 133-144.

OAKeshotT, M. (2000c) La actividad del historiador, en El racionalismo en la política y otros ensayos. México, FCE, 149-176.

OAKeshotT, M. (2000d) La voz de la poesía en la conversación de la Humanidad, en El racionalismo en la política y otros ensayos. México, FCE, 447-493.

OAKESHOTT, M. (2000e) El estudio de la política en la universidad, en El racionalismo en la politica y otros ensayos. México, FCE, 177-207.

OAKESHOTT, M. (2000f) Qué es ser conservador, en El racionalismo en la política y otros ensayos. México, FCE, 376-402.

OAKeSHOtT, M. (2009a) Las universidades, en La voz del aprendizaje liberal. Madrid, Katz/ Liberty Fund, 145-181.

OAKeshotT, M. (2009b) La educación política, en La voz del aprendizaje liberal. Madrid, Katz/Liberty Fund, 183-210.

OAKESHOtT, M. (2009c) El aprendizaje y la enseñanza, en La voz del aprendizaje liberal. Madrid, Katz/Liberty Fund, 67-91.

OAKESHOTT, M. (2009d) La educación: el compromiso y su frustración, en La voz del aprendizaje liberal. Madrid, Katz/Liberty Fund, 93-132.

OAKeshotт, M. (2009e) Un espacio de aprendizaje, en La voz del aprendizaje liberal. Madrid, Katz/Liberty Fund, 35-66.

Plotica, L. P. (2013) «This is Simply What I Do»: Wittgenstein and Oakeshott on the Practices of Individual Agency. The Review of Politics, 75, 45-68.

Sмith, T. W. (1996) Michael Oakeshott on History, Practice and Political Theory. History of Political Thought, vol. XVII, n. ${ }^{\circ} 4,591-614$. 
Sullivan, L. O. (2000) Michael Oakeshott on European Political History. History of Political Thought, vol. XXI, n. ${ }^{\circ} 1,132-151$.

Sullivan, L. O. (2014) Michael Oakeshott and the Left. Journal of the History of Ideas, volume $75,{ }^{\circ}{ }^{3} 3,471-492$.

Teorodo, A. y Guilherme, M. (2014) European and Latin American Higher Education Between Mirrors. Rotterdam, Sense Publishers.

Vera, H. A. (2003) Sociología y Sociedad del Conocimiento, en BoKser, M. y LIWERANT, J. (2003) Las ciencias sociales, universidad y conocimiento. México, unAm.

Williams, K. (2002) The Limits of Aesthetic Separatism: Literary Education and Michael Oakeshott's Philosophy of Art. Westminster Studies in Education, vol. 25, 2, 163-173.

Williams, K. (2007) Education and the voice of Michael Oakeshott. Exeter, Imprint Academic. Williams, K. (2009) Vision and Elusiveness in Philosophy of Education: R. S. Peters on the Legacy of Michael Oakeshott. Journal of Philosophy of Education, vol. 43, s1, 223-240. 
